\title{
A MIGRAÇÃO E O TRABALHADOR MIGRANTE NAS PÁGINAS DO BOLETIM CÁ e LÁ
}

\author{
Sérgio Daniel Nasser *
}

1 década de 1980 é um momento importante para problematizar a questão da migração temporária e permanente para a região de Ribeirão Preto. A chegada de vários trabalhadores de diversas regiões do país no local suscitou discussões sobre as transformações do espaço e sobre o direito de pertencimento na região ${ }^{1}$.

Nesse processo, o surgimento da Pastoral do Migrante de Guariba, no início dos anos 1980, e a proliferação dos centros de triagens em Ribeirão Preto e Franca, em 1989, apontam o conflito e as variadas concepções sobre como o espaço da região deveria se transformar e quais sujeitos deveriam ocupá-lo.

No artigo centro as atenções na análise do boletim Cá e Lá, a fím de perceber as construções sobre a questão da migração e sobre a imagem do migrante no periódico.

\section{O BOLETIM}

O boletim periódico Cá e Lá foi uma publicação resultante do contato entre as dioceses de Araçuaí, em Minas Gerais, e Jaboticabal², em São Paulo, e do contato com os trabalhadores migrantes. Produzido pela Pastoral do Migrante de Guariba - PMG, originouse em 1986 e circula ainda hoje, sendo concebido com o intuito de manter o diálogo entre pastorais e trabalhadores.

Os primeiros exemplares do boletim possuíam uma separação bem definida pela origem das notícias, cerca de três quartos do espaço eram ocupados por notícias oriundas da cidade de Dobrada, São Paulo, e o espaço restante por notícias do norte de Minas Gerais e do sul da Bahia, oriundas da diocese de Araçuaí. Os exemplares posteriores passaram a ser construídos com informações mais interligadas, ocultando as diferentes origens das notícias e construindo textos mais identificados por temáticas específicas do que pelo local de sua produção.

Em julho de 1987, o boletim adotou na primeira página a publicação de cartas de trabalhadores migrantes, de pessoas que permaneciam nas comunidades de origem dos trabalhadores e de agentes pastorais. Essas cartas eram escritas e enviadas à Pastoral do Migrante de Guariba para serem publicadas no boletim, e na maioria das vezes eram respostas a pedidos dos membros da Pastoral para que os trabalhadores relatassem suas experiências. Os conteúdos, geralmente, eram denúncias de descumprimento aos direitos trabalhistas por parte dos empregadores na região de Ribeirão Preto, baixos salários, comida ruim, vigilância armada nos alojamentos, pressão de supervisores e ameaças de demissão.

Nos primeiros anos, foram publicados seis boletins anuais com duas páginas em cada edição, sendo que a partir de 1989 até o final dos anos 1990 foram publicados entre oito e nove boletins anuais. No ano de 1998 o boletim passou a conter quatro páginas, e no início dos anos 2000 o número de publicações diminuiu, chegando a um boletim por ano, em virtude da escassez de verbas.

A tiragem do Cá e Lá foi de dois mil exemplares no primeiro ano de circulação. Em 1989 atingiu cinco mil exemplares e em 1995 chegou a sete mil. Nos últimos anos o número de exemplares reduziu-se para a tiragem de três mil.

O periódico era distribuído nas regiões de origem dos trabalhadores migrantes, enviados aos dirigentes ${ }^{3}$, sindicatos e paróquias que repassavam para a comunidade, e nas cidades da região de Ribeirão Preto, principalmente nos alojamentos das usinas.

\section{CONCEPÇÕES}

As páginas do Cá e Lá traziam informações sobre greves, acordos salariais, relação com os sindicatos e reivindicações acerca das condições de trabalho na safra de cana-de-açúcar. Além disso, continham comentários sobre encontros realizados por pastorais com trabalhadores migrantes, análise da conjuntura nacional e do processo migratório, orientação sobre a questão religiosa na vida do trabalhador, entre outros assuntos. 
$\mathrm{Na}$ análise de Irmã Inês Facioli, missionária escalabriniana que trabalha com a questão da migração para a região desde o início dos anos 1980, sendo atualmente responsável pela publicação do Cá e Lá, o intuito do boletim seria principalmente o de denunciar condições adversas de trabalho do migrante na região. Para Irmã Inês, uma das formas de atuação da Pastoral do Migrante na questão da exploração exercida por empregadores sobre os trabalhadores migrantes era a denúncia pública:

E essa maneira de tornar público era através do boletim Cá e Lá, tá, esse boletim Cá e Lá era distribuído mensalmente nos alojamentos e nesse boletim a gente colocava as cartas que os migrantes escreviam, alguns depoimentos, essas denúncias, então a situação se tornava pública tá, e esse mesmo boletim que era distribuido nos alojamentos era mandado também pra Minas e pra Bahia, pras regiões de onde eles vinham. (Irmã Inês Facioli. Entrevista: 11/10/2006.)

Irmã Inês é muito enfática ao atribuir enorme importância ao periódico, quando diz que na década de 1980 não se tinha notícias nos meios de comunicação sobre a questão das migrações e por isso o migrante era visto de maneira distorcida, relacionado à figura do andarilho, concluindo que à medida que se discute e também acho que esse boletim Cá e Lá né, criou muita consciência na região sobre essa questão da mobilidade humana. (Irmã Inês Facioli. Entrevista: 11/10/2006.)

A proposta de organização coletiva em oposição à luta individual perpassou as décadas de 1980 e 1990 nas páginas do Cá e Lá, com ênfase na união dos trabalhadores como forma de superar os problemas encontrados: $E$ un unidos e organizados que poderemos eliminar as feridas que machucam tantas familias de migrantes. (Boletim Cá e Lá, dezembro de 1986, p. 01.)

A opção individual é representada pelo ato de migrar, considerado um viés particular do sujeito para superar os problemas vivenciados. A opção coletiva é representada pela organização dos trabalhadores nas próprias comunidades, considerada nas páginas do boletim como exemplo de alternativa bem sucedida a se seguir:

..há muitas tentativas de pequenos projetos comunitários como forma de resistência: tendas de farinha, mutirões na roça, artesanato, legalização dos títulos de terra, hortas comunitárias, mobilizações pela Reforma Agrária, associações de saúde, creches... (Boletim Cá e Lá. Ano 02, nº 7, abril de 1987, p. 02.)

Percebe-se grande preocupação do boletim em manter o contato entre aqueles que migraram e aqueles que ficaram. A proposta de organização no próprio local de origem significava a manutenção dos laços sociais e afetivos criados em cada comunidade. Esses laços seriam desestruturados com a saída de trabalhadores e de famílias inteiras para outras regiões do país, enfraquecendo o poder de resistir daqueles que permanecem nas comunidades:

A organização no local de origem representa a única "saida" para os trabalhadores que migram forçadamente. A luta pela melhoria das condições de trabalho "lá" pode representar a luta pela própria sobrevivência. (Boletim Cá e Lá, junho de 1991, p. 02.)

Nos textos que compõem o periódico, a relação organização/ conscientização permeará parte considerável dos argumentos utilizados. No editorial do primeiro boletim, lançado em abril de 1986, este é apresentado com o objetivo de prestar serviços principalmente de informações aos migrantes.(Boletim Cá e Lá, abril de 1986, p. 01.)

$\mathrm{O}$ interesse em tornar pública a situação vivenciada e denunciada pelos trabalhadores migrantes revela um cenário de disputa na região de Ribeirão Preto, na qual o boletim Cá e Lá dialoga com a grande imprensa, procurando construir uma imagem diferente desses sujeitos em relação àquelas veiculadas pelos grandes meios de comunicação.

\section{CONFLITOS NA REGIÃO}

A produção do boletim $C a ́$ e $L a ́$ suscitou tensões, provavelmente advindas de grupos sociais que não reconheciam os direitos do trabalhador migrante na região, atacando muitas vezes, além do próprio migrante, outros setores que se posicionavam favoravelmente ao mesmo, como, por exemplo, determinados sindicatos e setores da Igreja.

Padre Garcia, integrante da Pastoral do Migrante de Guariba, relata que houve forte resistência de parte da sociedade quando os membros da Pastoral intensificaram na década de 1980 a discussão sobre a presença do migrante na região: nós mesmos encontramos essa resistência, nós mesmos de alguma maneira por muitas pessoas fomos também rejeitados pelo fato de sermos defensores. (Pe. Antônio Garcia Peres. Entrevista: 11/10/2006.)

Os conflitos de interesses e as disputas em torno da presença dos trabalhadores migrantes na região passaram a ser mais evidenciados nas páginas do periódico no final dos anos de 1980 e início dos anos de 1990, quando se adota a postura de tecer críticas mais diretas nos editoriais. (Boletim Cá e Lá, julho de 1991, p. 01.)

Além de criticar a postura dos grandes meios de comunicação da região de Ribeirão Preto por criminalizarem o migrante, os editoriais criticavam também as políticas públicas que visavam a reprimir sua chegada e permanência nas cidades da região.

Outra visão criticada é aquela de grupos sociais que constroem a imagem da região como local de riquezas e ausência de conflitos sociais e desigualdades, portanto, como modelo a ser seguido: 
Enquanto assistimos os meios de comunicação proclamarem com imponência e ostentação, que a região de Ribeirão Preto, compreendendo 86 cidades do interior paulista, com uma renda per capita de 50 mil por mês, considerada a 'Califórnia Brasileira', vemos ao lado disso retrocessos nos direitos já conquistados pelos trabalhadores, por exemplo a volta das 7 ruas; bem como o não cumprimento de algumas leis constitucionais...(Boletim Cá e Lá, outubro de 1990, p. 01.)

$O$ editorial acima se insere numa complexa disputa entre concepções sobre a região de Ribeirão Preto. Ele diverge dos diversos meios de comunicação que no mesmo período retratavam Ribeirão Preto como sendo a Califórnia Brasileira. Esse tipo de olhar sobre Ribeirão Preto não foi restrito à imprensa regional, adquirindo aspecto de propaganda nacional em grandes meios de comunicação. (Revista Manchete, 8 de julho de 1989, p. 69.)

A construção da imagem de um local imune à crise foi muito forte no final da década de 1980 e ainda hoje aparece ressaltada em muitos olhares que a grande imprensa nacional constrói sobre a região de Ribeirão Preto, principalmente quando noticia os números do agronegócio.

A idéia de uma Califórnia Brasileira foi contestada nas páginas do boletim Cá e Lá, pois apresentava a concepção de uma região supostamente sem conflitos sociais, beneficiada por um conjunto de relações sociais em que os interesses de todos eram atendidos. A contestação foi construída com o intuito de explicitar que nem todos se beneficiavam daquele modelo de desenvolvimento, criticado repetidas vezes nas décadas de 1980 e 1990 nas páginas do boletim.

\section{A RECEPÇÃo}

Muitas cartas de trabalhadores enviadas à $\mathrm{PMG}$ contêm diálogos sobre a distribuição e circulação do boletim:

Recebi os segundos folhetos também e todos foram distribuidos entre os companheiros aqui, e peço a vocês que continue me escrevendo pois fico muito feliz, e peço desculpas por não ter escrevido ainda. (Carta de Domingos Moreira Souza, 17/10/1989. Arquivo da PMG)

Pelas várias cartas comentando o recebimento do $C a ́$ e $L a ́$ e pela distribuição feita por sindicatos, pastorais e dirigentes de comunidades para suas áreas de influência pode-se deduzir que este foi um instrumento de circulação e discussão de idéias sobre questões relacionadas ao processo migratório.

A recepção do boletim provavelmente era muito ampla, devido ao alcance de um público extremamente diversificado e abrangente em termos econômicos, sociais e culturais. Além de ser destinado a regiões completamente diferentes, o público também não se restringia aos trabalhadores rurais migrantes, já que agentes pastorais, sindicalistas, trabalhadores urbanos e outros poderiam ter acesso ao periódico. Assim, as leituras sobre o conteúdo variavam muito.

Em carta enviada da cidade de André Fernandes, Minas Gerais, por Claudeci Pereira Lima, trabalhador que em 1988 se tornaria presidente do sindicato dos trabalhadores rurais, observa-se uma das interpretações sobre o boletim:

Mais o pessoal não está acreditando no Cá e Lá, e está indo para as grandes cidades. Este Cá e Lá trouxe um jeito de evitar a migração um abraço da comunidade de Porteira Nova. (Carta de Claudeci Pereira Lima, 29/11/1987. Arquivo da PMG.)

A leitura acima aponta uma das possibilidades de interpretação do periódico, apresentando-o como uma tentativa de frear a migração devido ao ataque às condições de trabalho encontradas no estado de São Paulo. A preocupação com tal leitura rendeu uma carta em resposta do Padre Antenor, membro da Pastoral do Migrante de Guariba, para Claudeci:

Recebemos sua carta e sentimos a sua preocupação em relação a tantas pessoas que migram também em sua comunidade. Através do Cá e Lá não pretendemos dizer se é para sair ou não. É hora que toda essa grande massa que migra perceba que o problema já não pode ser resolvido individualmente. Por isso insistimos que o povo busque organizadamente tentar resistir $e$ encontrar formas para permanecer na sua própria terra...exigindo se for necessário terra e meios pra viver com sua família. Na terra se as condições realmente não permitirem que se saia mas com algumas garantias para não ser mais um jogado nesse mundo de Deus. (Carta de Padre Antenor Dalla Vecchia, 08/01/1988. Arquivo da PMG)

Com o intuito de esclarecer a proposta de organização dos trabalhadores, a carta de Padre Antenor faz ressalvas para o boletim não ser lido como contrário à presença dos migrantes na região, postura que poderia asssemelhar-se à de outros setores da sociedade que no mesmo período atribuíam a tais sujeitos a responsabilidade por muitos problemas sociais do local.

Devido às múltiplas possibilidades de leitura dos textos do boletim, convém notar o possível conflito de interesses entre o posicionamento defendido pelo Cá e Lá e a vontade atrelada à necessidade que os trabalhadores de cada local possuíam de migrar, principalmente para a safra de cana-deaçúcar. Ao apontar a migração como opressão para os trabalhadores, o Cá e Lá sugeria a permanência e a organização no próprio local de origem.

Em alguns editoriais há avaliações sobre o trabalho realizado, as quais culminam no otimismo em relação à eficácia da comunicação estabelecida via boletim com os trabalhadores migrantes: 
Companheiro, está chegando até você o quarto número do "Cá e Lá", pelo que estamos percebendo Ele está mexendo com a vida dos trabalhadores. Ele está sendo motivo de bate-papo e discussão a respeito da situação em que vivem os trabalhadores. (Boletim Cá e Lá, julho/agosto de 1986, p. 01.)

No primeiro ano de circulação, o trabalho realizado no periódico é apresentado com entusiasmo por contribuir com a discussão coletiva. No ano seguinte, a análise é reiterada e sugere-se grande aceitação por parte dos leitores em um editorial que comenta as cartas recebidas naquele período:

Parece-nos que desta forma os migrantes e suas comunidades vão assumindo este jornalzinho como seu órgão de comunicação. Assim vão acompanhando mais de perto as dificuldades encontradas e, como "povo disperso", busca comunitariamente saidas para seus dramas..." (Boletim Cá e Lá, julho de 1987, p. 01.)

\section{CONSTRUÇÕES SOBRE $O$ TRABALHADOR MIGRANTE}

Os conflitos de interesses acima relatados permitem pensar na complexidade das relações sociais estabelecidas na região de Ribeirão Preto e permitem analisar como o trabalhador migrante foi retratado por esse boletim que se colocava como defensor de seus interesses.

A construção da imagem do migrante no periódico Cá e Lá difere, evidentemente, da imagem desse mesmo sujeito formulada nas páginas dos grandes meios de comunicação, em específico nas páginas do jornal $A$ Cidade, a qual tendia a criminalizar a presença de tais sujeitos na região. Entretanto, isto não quer dizer que ela tenha sido homogênea e simplista, pelo contrário, foram elaboradas diversas abordagens sobre o migrante, principalmente nos editoriais, situados na parte superior da primeira página do boletim e elaborados em forma de textos curtos e destacados do restante das reportagens.

O primeiro grande conjunto de abordagens sobre o trabalhador migrante destaca a construção de um povo sofredor, evidenciado no seguinte trecho:

Migrante é que nem folha seca, que o vento leva para onde quer...; Migrante é que nem pomba, aonde vai tem um caçador na mira; Migrante é uma máquina que os poderosos usam para aumentar suas riquezas...; Migrante é que nem passarinho: voa de galho em galho e nunca encontra sossego, só que o passarinho canta e o migrante chora ${ }^{4}$. (Boletim Cá e Lá, junho de 1991, p. 02.)

A formulação acima de um povo respectivamente caçado/explorado/triste seria comum nos boletins em todo período analisado, adquirindo outros adjetivos como povo necessitado, maltratado, subornado, enganado, traido, oprimido, ferido, que convive com dramas, vítima da falta de programa sério que venha assegurar uma vida digna.

Nessa primeira formulação, algumas reflexões estabeleceram paralelos entre a experiência vivenciada pelos trabalhadores migrantes com outras experiências históricas de sofrimento e exploração de um povo. Em editorial de maio de 1988, há uma dessas construções que comparam os migrantes negros (escravos) trazidos da África com os trabalhadores migrantes da região de Ribeirão Preto, ambos como contribuintes do país com o próprio trabalho, mas sem muito futuro para si e para os seus. (Boletim Cá e Lá, maio de 1988, p. 01.)

A construção da imagem de um povo sofredor e explorado parece uma forma de justificar a escolha do trabalho da Pastoral do Migrante junto a esse conjunto da população e de justificar também as' cobranças direcionadas a autoridades municipais e a outros setores da sociedade para que formulem projetos para a solução dos problemas enfrentados por aqueles que migram.

No trecho destacado, analisa-se a conseqüência imediata da migração, formulada na comparação da experiência do migrante com o passarinho, que em outros textos se transforma na figura mais específica da andorinha para caracterizar um povo que não se fixa em um lugar determinado.

A imagem do passarinho possui uma relação direta com a formulação da idéia de um povo disperso. Em uma das construções, destaca-se o caráter de incentivar a organização dos trabalhadores, que pode ser observado quando diz que Moisés foi mandado por Deus para unir um povo que era escravizado no Egito por viver disperso, concluindo que:

Pois bem, hoje o povo migrante está sendo obrigado pelo sistema que vivemos, a se dispersar, a não ter um rosto, a ficar dividido, a perder suas raizes... Isso tudo para estar às disposição do sistema que o empurra de cá pra lá, num vaivém contínuo. (Boletim Cá e Lá, julho de 1987, p. 02)

É comum no boletim o argumento que entrelaça aspectos bíblicos e históricos com as experiências dos migrantes, com intuito de refletir concomitantemente sobre as questões religiosas e mundanas.

No trecho acima, é importante notar que a vida dispersa do trabalhador migrante é lida como responsável direta pela perda das próprias raízes, ou seja, a perda das referências. Em uma construção mais extremada sobre o mesmo assunto chega-se a afirmar que muitas vezes vivem como estrangeiro no próprio país. (Boletim Cá e Lá, setembro de 1993, p. 01.)

A noção de que o povo migrante é disperso e sem identidade, pelo fato de a migração causar o desenraizamento do 
povo, aparece nas páginas do documento Igreja e Problemas da Terra, de 1980 , produzindo na $18^{\text {a }}$ Assembléia da Conferência Nacional dos Bispos do Brasil, no qual se procurou delimitar as frentes de ação da Igreja Católica.

Num pólo oposto à construção povo sofredor e povo disperso, é construída a imagem de uma gente que resiste aos problemas enfrentados diariamente:

Distantes da Terra-Mãe, negociada pelo capital e da Família-Nicho, dividida pela migração, enfrentam com coragem e fé as durezas e enganos constantes a que são submetidos. Buscam proteção e se deparam com a traição. No entanto, conscientes das pequenas e grandes conquistas, que acontecem e podem acontecer, continuam firmes, fazendo a História. (Boletim Cá e Lá, agosto de 1988, p. 01).

Coragem, fé, firmeza e consciência são características que qualificam o homem migrante para continuar nas disputas cotidianas e fazer História. A imagem do povo que resiste vem sempre relacionada à idéia de condições adversas de sobrevivência:

Estes bravos guerreiros que trazem no rosto marcas de uma dura e cruel luta pela sua sobrevivência e de seus familiares, que ficaram na região de origem, trazem consigo a esperança de um futuro melhor. (Boletim Cá e Lá, junho de 1996, p. 01.)

Em outros exemplares analisados, a idéia do povo guerreiro que enfrenta a dura realidade aparece na forma de outros adjetivos, como povo persistente, lutador, valente, crente, insistente, entre outros.

A idéia abordada no trecho acima, de um futuro melhor, geralmente é relacionada com a expectativa do trabalhador migrante e nunca com a experiência vivenciada, pois esta, por ser lida sempre como uma experiência de sofrimento e enfrentamento de condições adversas, está relacionada diretamente com a idéia de um futuro pouco promissor.
$\mathrm{Na}$ perspectiva de futuro pouco otimista para o trabalhador migrante surge um outro campo de imagem construído, o qual ressalta a idéia do trabalho:

É pelas mãos de cada migrante que a terra da região canavieira recebe a semente, o cultivo e a colheita. Essas mãos 'feias' porque calejadas, mas BELAS PELO TRABALHO QUE PRODUZ. (Boletim Cá e Lá, junho/ julho de 1997, p. 01)

Nessa perspectiva, o migrante aparece como o trabalhador e o desdobramento de tal construção leva a crer que seu intuito é o de legitimar a presença desses sujeitos na região, contestando-se a idéia de que são eles que trazem os problemas para o local.

Alguns trechos do periódico respondem de forma ainda mais direta a tais acusações:

É preciso que as prefeituras dessas cidades tomem as devidas providências, porque os migrantes não só 'buscamo dinheiro', como dizem... Além de produzirem riquezas com seu trabalho, compram no comércio, que geram impostos para o município. Com a chegada dos migrantes, as vendas dobram no comércio de várias cidades da região.(Boletim Cá e Lá, agosto/ setembro de 1991, p. 01/02.)

O argumento central dessa construção é o de que os migrantes são trabalhadores que geram riquezas para a região de Ribeirão Preto, portanto estes se tornam sujeitos que merecem todo apoio das prefeituras para a garantia de condições dignas de moradia. Em outras palavras, pede-se no texto acima que eles sejam tratados como cidadãos com direitos iguais aos outros, e não como sujeitos excluídos e diferentes do restante da população desses lugares.

Uma alternativa encontrada também para disputar a concepção de que os migrantes devem ser tratados como cidadãos na região consiste em analisálos como sujeitos que não possuem condições de enfrentar o mercado de trabalho moderno e, portanto, por serem considerados desqualificados (Boletim Cá e Lá, abril/maio de 1995, p. 01), necessitam da ajuda de todos para superar as dificuldades.

Com esse argumento, que aparece em poucos editoriais se comparados com as construções analisadas até aqui, clama-se pela piedosa ajuda de todos para auxiliar os migrantes que necessitam porque ainda não se pensa e não se investe a partir dos fracos. (Boletim Cá e Lá, março de 1995, p. 01).

Em linhas gerais, as imagens construídas sobre o migrante no boletim Cá e Lá refletiam as concepções da Pastoral do Migrante, a qual, ao se posicionar como defensora desses sujeitos, tendia algumas vezes a vitimálos, colocando-os sob o universo das ações assistenciais pastorais.

As diversas construções da imagem do migrante no boletim Cá e Lá analisadas acima revelam a complexidade da disputa cotidiana pela legitimidade de pertencimento na região de Ribeirão Preto e os múltiplos olhares existentes no interior de um mesmo grupo social sobre a questão da migração e o trabalhador migrante.

\section{* Sérgio Daniel Nasser é Mestre em História Social pela Universidade Federal de Uberlândia.}

\section{NOTAS}

1 - Este artigo origina-se das análises realizadas na dissertação " $E u$ vou entrar no mundo": experiências de trabalhadores migrantes na região de Ribeirão Preto 1980 2007.

2 - É na Diocese de Jaboticabal, interior de São Paulo, que a Pastoral do Migrante - de responsabilidade direta dos/as Missionários/ as Escalabrinianos/as - tem sua sede, estando instalada, a partir do início dos anos de 1990 , na cidade de Guariba, tendo sido, anteriormente, na vizinha cidade de Dobrada.

3 - O dirigente era escolhido pelas pessoas da própria comunidade ou pelo padre da paróquia local e ficava encarregado de estabelecer o contato entre os membros de uma comunidade e a paróquia.

4 - A PALAVRA DO MIGRANTE. Boletim Cá e Lá. Ano 06, nº 40, junho de 1991, p. 02. 